\title{
Unani Perspective in the Prevention and Treatment of Psychiatric Disorders
}

\begin{abstract}
Mohd Usman' ${ }^{1}$, SM Safdar Ashraf ${ }^{2}$
Abstract

Mental health is an important aspect of human health. It is the need of hours to preserve this dimension of health. The positive dimension of mental health is stressed in World Health Organization's definition of health as a state of well-being in which the abilities are realized by individual, can cope with normal stress of life can work productively and fruitfully and is able to make a contribution to his or her community. Mental disorders are increasing due to more stress level. One in four people in the world are affected by mental or neurological disorders at some point of lives. Mental disorders include depression, bipolar affective disorder, schizophrenia and other psychoses, dementia, intellectual disabilities and developmental disorders including autism. According to world health report depression is a common mental disorder and one of the main causes of disability worldwide. Globally, an estimated 350 million people are affected by depression. Women are more affected than men. Unani system of medicine is the only system which intervenes with Asbab-e-SittaZarooriya (six essential causes) especially by HarkatwasukoonNafsani (Bodily \& Psychic movement) and Naumwayaqza (sleep \& wakefulness). In this regard TadeelRuh is the basic concept to keep away mental disorders. Equilibrium between these two AsbabeSehat(causes of health) is enough to keep away mental problems. In spite of that there are a lot of UnaniMufridat (single) and Murakkabat (compound) drugs for examples Musakkinat (Sedative), Mufarrihat (the drug which induce pleasurable effect), Mubrridat (the drug which induce cold effect) and MuqwaiyeDemagh (brain strengthener) which can not only preserve mental health but also keep away mental disorder such as Nisyan (Dementia), Insomnia, Headache, Depression and other mental problems.
\end{abstract}

Keywords: Six Essentials Factors (Asbab-e-Sitta Zarrroriya), Sleep \& Wakefullness (Naumwayaqza), Sedatives (Musakkinat)

\section{Introduction}

Unani medicine is one of the systems of medicine which has scientific approach and depends on the holistic base. The great physians of Unani medicine like Hippocrate (Buqrat), Abu Bakr Bin ZakriaRazi, Ali Bin RabbanTabri, has described in detail about NafsiyatiAmraz or Mental Disorders or Psychiatric disorders.According to world health organization it is a state of wellbeing in which individual realize his or her own abilities, can cope with normal stresses of life, can work productively and fruitfully and is able to make a contribution to the community. ${ }^{(1,2)}$

\section{Diseases Burden}

One in four people in the world will be affected by mental or neurological disorder at some point in their lives. About 350 million people were estimated to be suffering from neuropsychiatric condition. ${ }^{(3)}$ According to new estimates of prevalence of Depression, released by the World Health Organization, the number of people living with depression increased

${ }^{1}$ Assistant Professor, ${ }^{2}$ Professor and Chairman, D/O TST, Ajmal Khan Tibbiya College, AMU, Aligarh.

Correspondence: Dr. Mohd Usman, D/O TST, Ajmal Khan Tibbiya College, AMU, Aligarh.

E-mail Id: mousman2010@gmail.com

Orcid Id: http://orcid.org/0000-0001-8563-4798

How to cite this article: Usman M, Ashraf SMS. Unani Perspective in the Prevntion and Tretment of Psychiatric Disorders. $J$ Integ Comm Health 2017; 6(3\&4): 26-30.

Digital Object Identifier (DOI): https://doi.org/10.24321/2319.9113.201707

ISSN: 2319-9113 
by more than $18 \%$ between 2005 and 2015. ${ }^{(4)}$ Depression is also the largest cause of disability worldwide. According to the latest estimates from World Health Organisation, more than 300 million people are now living with Depression. ${ }^{(5)}$

More than $80 \%$ of this disease burden is among people living in low- and middle-income countries. Depression affects people of all ages, from all walks of life, in all countries. It causes mental anguish and impacts on people's ability to carry out even the simplest everyday tasks, with sometimes devastating consequences for relationships with family and friends and the ability to earn a living. Depression is a common mental illness characterized by persistent sadness and a loss of interest in activities that people normally enjoy, escorted by an inability to carry out daily activities, for 14 days or longer.

In addition, people with depression normally have several of the following; a loss of energy; a change in appetite; sleeping more or less; anxiety; reduced concentration; indecisiveness; restlessness; feelings of worthlessness, guilt, or hopelessness; and thoughts of self-harm or suicide. The new estimates have been released in the lead-up to World Health Day on 7 April, the high point in WHO's year-long campaign "Depression: let's talk". The overall goal of the campaign is that more people with depression, everywhere in the world, both seek and get help. With such a magnitude of mental disorders it becomes necessary to promote mental health services for the well-being of general population, In addition to provide treatment of mental illness.

\section{Classification of mental disorders (According to modern system)}

The International Classification of diseases (ICD) is an international standard diagnostic classification for all general epidemiological and many health management purposes, published by WHO. It now exists in its tenth revision. Chapter $\mathrm{V}$ is relevant for mental and behavioural disorders.

The ICD-10-classification for mental disorders consists of 10 main groups:

- F0: Organic, including symptomatic, mental disorders

- F1: Mental and behavioural disorders due to use of psychoactive substances

- $\quad$ F2: Schizophrenia, schizotypal and delusional disorders

- F3: Mood [affective] disorders

- F4: Neurotic, stress-related and somatoform disorders

- F5: Behavioural syndromes associated with physiological disturbances and physical factors

- F6: Disorders of personality and behaviour in adult persons

- F7: Mental retardation

- $\quad$ F8: Disorders of psychological development
- $\quad$ F9: Behavioural and emotional disorders with onset usually occurring in childhood and adolescence In addition, there is a group of "unspecified mental disorders"

For the chapter of mental disorders, every main group has the identification letter " $F$ ". For each group exists more specific subcategories.

\section{Classification of mental disorder according to Unani system of medicine}

KharabieAql (mental disorders) can be classified in three stages in Unani system of medicine, in first stage there is hallucination called as "If Hiss is Fasid (disturbance in sensation) butFaham (Inelegancy) is correct". Second stage characterized by disturbance in Faham, however Hiss is normal for example a person throwing pots of kitchen in lower side by taking name of each pot that means sensation is correct but Fikr (thinking) is Fasid(disturb). Third stage is characterized by deterioration in both Hiss and Faham. It is rare than rarest.

\section{Unani classification according to powers of the brain}

It is divided in three parts as Psychic power (QuwateNafasania) which has QwateHissia (Sensory power) and QwateHarkiya (Motor power) secondly QwateHissia again have Six external powers (Hawasekhamsazahira) and Six internal powers (Hawasekhamsabatina), third one which is very important in mental disorder is Qwat-e-Mutakhaila (power of thinking) and QawateHisemushtarak (power of imagination) lays in anterior ventricle of brain. Hallucination results due to disturbance in Mutakhaila such type of patient is crying and in his perceptions; he is listening the musical sounds and looking some strangers. ${ }^{(6)}$

The second faculty is that which the physician called as Qwatemutafakkira or thinking faculty. The seat of this faculty lies in the middle ventricle of brain. If there is any disturbance in power (Quwwat) then the patient behave like a person who locked himself in a room and throw all subjects of the room towards the people through open window. The cause of this is the Cold bad humour (Baridraddikhilt) which produces disturbances in the brain. The third faculty described by the physician is the faculty of Qwatehafiza (memory and recall). It lies in the posterior ventricle of brain. ${ }^{(6)}$

\section{Unani concept in the etiology of Psycological problems}

Unani Medicine deals with Anasir (elements) as the basic component of the body, they interact with each other to form molecules these molecules, on further interaction form the four basic fluids (Akhlat) of the 
body vizBalgum, Dam, Safra and Sauda. These form the organs and in their appropriate proportion perform the physiology of the body with the help of organs. When there is any abnormality among Akhlat (Humors) it manifests in various pathologies. These pathologies are governed by the AsbabesittaZarroriya(six essential factors of life) i.e. Hawa,(Air), MakoolatwaMashroobat (foods and drinks),Harkatwa Sukoone Badni( rest and body functions),Harkatwa Sukoone Nafsani (emotions and psychological rest), Naumwa Yaqza (sleep and wakefulness) and Ahtabaswalstafrag (retention and evacuation). When adhered to these factors in their appropriate measure promotes health and when disturbed in their appropriation predispose the body to humoral imbalances.

When there is imbalance inemotions and psychological rest (HarkatwasukoonNafsani) and Naumwayaqza (sleep and wakefulness) it results in disturbance in mental faculties, According to Avicenna (IbneSina) there are three fundamentals for health preservation viz Exercise, diet and sleep. This implies that along with the balance of emotions and psychological rest (HarkatwaSakoonNafsani) and balance (tawazn) of sleep and wakefulness (NaumYaqza) is equally responsible to keep away mental disorders. There is the importance of physical exercise (Riyazat) as well as (MakoolwaMashroob (Diet) for betterment of psychic faculty. In this regard highly nutritious diet along with light exercise could play a critical role to maintain psychic faculty.

Correlation of Sleep and wakefulness (Naumwayaqza) and Amraze Nafsania (mental disorders)

Sleep is quite similar to rest, and wakefulness to movement. According to new concept it provides the brain a period to repair cellular damage and to restore energy level within the cell. It induces BaroodatwaRatoobat (coldness and moistness) in the body. It strengthens QuwateHaiwania(vital forces), Rooh (Pneuma), and promote digestion. Sleep (Naum) affords Relaxation of organs (TaskeenAaza) by abolishing tiredness and prepares the body for further work. It is necessary for mental health and Psychic power (QuwatNafas). ${ }^{(6,7,8,9)}$

It is obvious that Space (Takhalkhul), emaciation of organs (ZoafeQuwa) and excessive Loss of psychiatric power (Tahallul of Rooh Nafsani) are the resultant of sleep disturbances and also these factors form the foundation of Mental disorders (NafsiyatiAmraz). ${ }^{(10)}$ Disturbed or improper sleep would affect nervous system so to avoid mental disorder one should take optimum required sleep. According to Majoosi sleep provides assistance to brain and Hawasekhamsabatina(five inner powers) and Quwwatelradi (will power) (11) If sleep finds emptiness or a humour which is not amenable to digestive power it disperses the Humour (khilt). When wakefulness is excessive it vitiates the temperament of the brain by producing dryness. Thus it causes imbecility, burns up the humours and causes acute diseases. One the other hand excessive sleep causes an opposite effect. It produces dullness of psychic faculties, heaviness of head and cold diseases. This is because excessive sleep prevents dispersion. ${ }^{(12,13,14)}$ Wakefulness stimulates the appetite by dispersing matter. It impairs digestion by dispersing the power. Caught between sleep and wakeful ness and rolling about in bed, is the worst of all states. Sleep also affects the secretions of endocrine hormones and exerts inhibitory affect. ${ }^{15-18)}$ Hence sleep is an important and an integral part of the treatment of such disorders. Oral use of sweet almond oil (RoghanBadamShireen), lettuce (kahu) and compound formulations like (SharbatKhashkhash) are beneficial in inducing sleep due to their sedative and tranquilizing properties. ${ }^{(19-25)}$

Correlation of emotions and psychological rest (Harkatwasukoon Nafsani) and Mental disorders (AmrazeNafsani)

All psychiatric conditions are followed by either inward or outward movement of Pneuma or Rooh which may either be sudden or gradual. The outward movement of Pneuma or Rooh is followed by the coldness of interior. Sometimes this movement is excessive; HencePneumaorRooh get dispersed both the interior and exterior become cold and a severe syncope or death follows.The out ward movement of Pneuma or Rooh is either sudden as in anger or gradual as in pleasure and happiness. The inward movement of Pneuma or Rooh is either sudden as in terror or gradual as in sorrow. Sometimes Pneuma or Rooh moves simultaneously in two directions. It happens when an emotion involves two impulses i.e. worry because it produces anger and gloom and give rise to two different movements. Or shame which causes the Pneuma or Rooh first contact towards the interior and when reason and good judgement are restored, to expand and rise towards the exterior. Applying basic knowledge about the movement of Pneuma or Rooh, one can implement the concept of Normal consistency of Pneuma(TadeeelRooh) as per the condition.

Prevention and treatment of psychiatric problems in Unani system of Medicine

The treatment of the diseases and correction of the abnormal process can be done with the help of four modes of treatment for examples as IlajBilGhiza( diet therapy) followed by Ilaj Bit Tadbeer ( regimental therapy), IlajBilAdvia (drug therapy) and IlajBilYad surgery.

\section{IlajBilGhiza (DeitoTherapy)}

Vitisvinifera (Angoor) is effective in degenerative nervous diseases. Clinical trials have proven its efficacy in Alzheimer's diseases. Gourd and cucumber are recommended amongst the vegetables to patients suffering from chronic stress. 
Both are documented diuretics which aid in the excretion of pathological Melanchole. Besides this Lagenariasiceraria (kaddu) is also beneficial in delirium. Among the fruits, watermelon, pomegranate, sugarcane and grapes are helpful. ${ }^{(26,27,28)}$

\section{Ilajbittadbeer (Regimenal Therapy)}

The regimens that are prescribed for chronic stress and psychiatric disorder are:

Venesection (Fasad): basilic or saphenous veins should be dissected to drain the pathological melanchole circulating with the blood (29) Sauna (Hammam): cold water or lukewarm water can be used for this purpose. $(30,31)$ Massage (Dalak): Light massage with Viola Odorata (Banafsha) oil or almond oil is advisable. Shower (Natool): diluted rose water, LactulaSativa(kahu) decoction and Viola Odorata (banafsha) are prescribed due to their exhilarant and sedative property. Seitz bath (Abzan): decoction of LactulaSativa (kahu) and Viola Odorata (banafsha) are advised. Cupping (Hijamath): this should be done on the shoulders.

\section{IlajbilDawa}

Usoolellaj (Principles of treatment) and Ilaj (treatment)

Arkhijanas a Unani philosopher treats loss of memory with excessive Taskheen along with cupping and DawaeKhardal. If loss or weakness of memory take place it means that there is sue mizajbarid in the Brain (Dimag), that's why on the basis of ilajbiljidTaskheen is necessary. A case history narrated by ZakriaRazi (Razes) that a farmer and philosopher got loss of memory Musakhin and Murattibtadbeer are beneficial. ${ }^{(32)}$

Intervention with kaefiat (qualities) and Temperament or Mizaj

Zehankikharabi ye alamathai sue mizajharki. Loss of Nafsaniaf'al and motor and sensory system indicates sue mizajbarid. Insomnia indicates yabusatedimagh. Insomnia and deterioration in the mind indicates hararat and yabusat Dimag. Excessive sleep with loss of motor and sensory system indicates Barudatwaratubatdimag. Sleep and deterioration in the mind indicates Hotness and moistness of brain (Haratwaratubatdimag). Insomnia and loss of motor sensation indicates (Coldness and Dryness)Barudatwayabusatdimag. Liquar (Sharab) is bad for brain. Ghalizjism (Morbid body) does not produceLateefzehan(Sharp brain).Ratoobat(Moistness) produce dullness in brain while yabusat (Dryness) produce sharpness of brain.

\section{For the improvement of Qwate Hafiza}

Kundur 105 gram, Filfil 35gram, make fine powder and use for 40 days 4-5 grams daily or up to 9 grams empty stomach once a time. ${ }^{(32)}$

\section{Majoon for Quwwate Hafiza (Memory power)}

Kundur 175 grams, Filfil 35 grams, wij 35grams, saad 70 grams, hailasiyah 70 grams, Zanjabeel 70 grams, Shahadbiladur 35 grams Shahad equal to all medicine.(32)

\section{For enhancing power of brain}

Hammam is beneficial, labob, phaloda and kaseerulghiza (multinutritious)makolat (drinks) are very beneficial. Bundiq andBadam with sugar are beneficial in enhancing brain. (32) Eating Khardal and applying its paste along with Jundbaidsatar on posterior part of brain is beneficial in Nisyan (Dementia) Further research is also required. Continuous and excessive use of onion is harmful and deteriorates the brain and induces dementia. Excessive use of corriandor (Dhaniya) is bad for brain. Kundur is good for brain activity further research is required. Baladur is good for Dementia. (32)

Excessive drinking of water is bad for brain due to the fact that it induces Coldness and moistness(Barodat and Ratobat)in Brain. Zanjabeel is good for QuwwateHafiza(memory power) (32)Sad kufi is good for brain(32)Mushk is MuqawwiDimagh and MujafifeDemagh. Powder of Elephant's teeth is good for SehateHifz. Walking is beneficial for enhancing brain power and movements of hands are also beneficial. (33-38)

\section{Conclusion}

Mental disorders however are increasing day by day but with the application of Unani concept of treatment and prevention they can be managed. There are a lot of Unani medicine and techniques for example Tila (paste), DalakeKhisn(Massage with rough cloth),Nutool (with Unani Medicine) or with goat milk), Tabreed(with RoganeKaddu, RoganeLabbobe Saba etc),Taskheen (with RoganeBadamshireen) etc by these ultimate and natural Tadabeer we can challenge these disorders. Further researches are required on Kundur and Biladur or other drugs for their important role in depression, dementia and other disorders on modern parameters to validate these statements.

\section{Conflict of Interest: None}

\section{References}

1. WHO. Strengthening mental health promotion. Fact sheet 220. Geneva: WHO; Revised 2001.

2. Pankaj, Adarsh, Sunderlal Text book of community medicine CBS Publishers618 fourth edition 2014.

3. Park K. Park's Text book of preventive and social medicine BanarsidasBhanot publisher, Jabalpur 770, $21^{\text {st }}$ Edition 2011. 
4. WHO The world health report; metal disorder affect one in four people. Press release WHO/42 Geneva.

5. WHO. "Depression: let's talk". Fact sheet. Geneva: WHO; Revised 2017.

6. IbnSina Al qanoonFilTib English Translation JamiaHamdard New Delhi 2003Pno.155.

7. htpp://www.econline.net/Knowledge/Article/ Sleephygiene.html (22.04.08).

8. IbnRushdKitabulkulliyat. New Delhi: CCRUM, Dept. Of AYUSH, Ministry of Health and family well fair Govt. of India; 1987.345,348,253.

9. Khan A H Majmul Bahrain, Luknow: Matba Munshi Nawal Kishor 1294 Hizri.239.

10. Zakriya Razi. Kitabul Mansoori New Delhi CCRUM, Dept. Of AYUSH, Ministry of Health and family welfare Govt. of India; 1991.152.

11. Begum S.J. Bhopal. Tandrusti. Lahore: Union Stean Press.

12. Begum S.J. Bhopal. Khanadari Part 2 or HifzSehat Bhopal: Matabae Sultan;1916.25.

13. Sabit Bin Qurrah Zakhira Sabit Bin Qurrah Urdu translation by Ali S.A) Aligarh Lethorrkle printers, C;28, Medical Enclave.A.M.U;1987.3-4.

14. Majoosi Ali Bin Abbas KamilusSana’ah (Tranlated by Kantoori GH) Vol.1 Lucknow: Published by MunshiNawal Kishore; 1889,240,290,292.

15. Van Cauter E, Turek FW. Endocrine and other biological rhythms. Philadelphia: In De Groof L J (eds), Endocrinlogy, W.B. Saunders;1995.2487-2548.

16. Pannain, Cauter EV. Modulation of endocrine function by sleep- Wake homeostasis and circadian Rhythmicity. Sleep Medicine Clinics.2(2):147-159.

17. Luboshitzky R. Endocrine activity during sleep. JPEM AfulaEdocrine Institute, Haemak Medical center;2000:13(1):13-20.

18. Sleep Quality and endocrine markers of sleep quality htpp://www.macses.ucsf.edu/Research/Allostatic/ Notebook/sleep htm cited on 2.04.2017.

19. Ibn, SinaQanoon fit Tibb, 4th Vol, (IHMMR, Hamdard, New Delhi, India). 1987

20. Khan S, IlaajulAmraaz Urdu, (MatbahMunshiNawal Kishore), 1982 pg 39.

21. Jurjani, ZakhiraKhawarzamShahi, Vol V Chap 8 pg 11-13, Vol VI pg 41-42 Chap2 pg38, Cap 3 pg 41(MaktabaMunshiNawal Kishore, Lucknow, India).

22. Kabiruddin M, SharahAsbaab, (Hikmat Book Depot, Hyderabad,) 1980 Vol 1pg113-127 Vol 4, pg101-106.

23. Razi, Al Havi fit Tibb, 1st Vol, (DairatulMuarif Al Usmaniya, Usmaniya University, Hyderabad, India). 1974.

24. Azam Khan, Ikseer e Azam, 1st Vol, pg 190 (Matbah Munshi Nawal kishore, Lucknow, India), 1847.

25. Majoosi I Abbas, Kamil us Sana, Matbatul Kubral Aamirah, Greece, 1294AH, Vol II, Chap 6-7 pg201, Chap 23, pg31, Chap 25 pg 223.
26. Ghani N, Khazainatul Adviyah, (Anjuman Faroogh Tariekh e Tibb e Unani (Islamiya), Lahore, Pakistan), 1992 Vol I 492-494, Vol II 581, 585, 532,537 Vol II 249, 259, 277, 280, 713, 716.

27. Baitarlbn, Al JamiulMufradaat, (Al Matba al Ameera) 1291AH.Vol I 54-56 Vol II 180-183.

28. Azam Khan, Muheet e Azam, Kahu, MatbahNizami, Kanpoor, 1867pg 22 ,Vol IV, Malkangini, pg 42, Vol 4, part I, Kishneez, pg83, part I Kafoor, pg 9 Vol 4 , part I.

29. Al QufMasihi AAFI, KitabulUmdaFilJarah, Vol I, CCRUM, 1986 fasadpg 185, hijamath194.

30. Jean E Loving, Massage Therapy, 1998, Appleton \& Lange, Connecticut, Pg 246.

31. Dawn Carroll \& David Bowsher, Pain Management \& Nursing care, 1993, Butterworth - Heinemann Ltd, Oxford.

32. Razi Alhawi fit tibVol 1 CCRUM New Delhi p.no. 7884, 1997.

33. Anonymous, Wealth of India, NISCAIR, New Delhi, India. 2007 Kahu, pg 11, Vol 4, 2005, Asgand pg 583, Vol 10 spw, 2005,Malkangini pg 412,Vol 3-ca1992,Kishneez pg 203,supplement Vol 2-d-cy,2007 Darchini pg 582, Vol 3 caci 1992,Kafoor pg 575,Vol 3 ca,ci,1992,Ustokhuddus pg 47,Vol 4-2-m,2005Asrol pg 383, Vol 3 ph-re,2005,Babrenj boyapg 332,Vol 4 I- m,2005Badaam pg 253,Vol 3 ph-he, 2005,Amla Vol 3 ,-d-e , 2006, pg 168.

34. Anonymous, Culpepers Complete Herbal and English Physician, Magna Books, Magna Road, Leicester. 1992 Ustokhudoos85, kahu 84, babuna 32

35. C. P Khare, Indian Medicinal Plants, Springer India Pvt Ltd, 2007Asgand 717, Malkagni 134, Kishneez 174, Darchini 150, Ustokhuddoos 365, Asrol 538, Badranjboya 406, Baboona 400, Amla 238, Brahmi77, Kafoor148.

36. Anonymous, Indian Medicinal Plants, Orient Longman Ltd, Madras, 1995. AsgandVol V pg 409, BrahmiVol I pg 23, malkangniVol II pg 47, kishneezVol II pg 184, DarchiniVol II pg 87 KafoorVol II pg 81, AsrolVol IV pg 409, BadaamVol IV, Pg 363.

37. M.P Singh, Himadri Panda, Medicinal herbs with their Formulations, 2005, Daya Publishing House, Delhi. Kahupg 519, Vol II, Asgand ,pg 889,Vol II, Brahmipg 145, Vol I, Malkanginipg 600, VollI,Kishneezpg 292, Vol I, Darchinipg 254, Vol I, Ustokhudduspg 525, Vol II, Babreyboya? pg 565, Vol II, Babunapg 240, Vol I, Embilicaoffencialspg 374.

38. Baghdadi IbnHubal, KitabulMukhtaraat fit tibb, CCRUM, 2005. AmlaVol IV pg 63, BabunaVol II pg 74, BadranjboyaVol II pg 75, UstokhudoosVol IV, pg 51, Kafoor, Vol II pg 170, DarchiniVol II pg 100.

Date of Submission: 2018-01-19 Date of Acceptance: 2018-02-20 